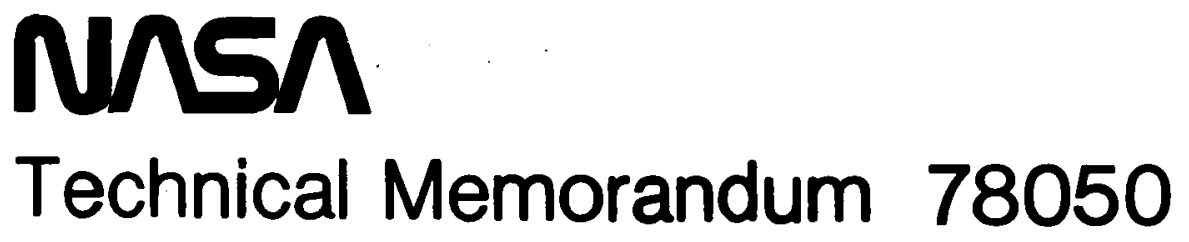

ERROR ANALYSIS FOR RELAY TYPE SATELLITE-AIDED SEARCH AND RESCUE SYSTEMS

J. W. Marini

SEPTEMBER 1977

National Aeronautics and

Space Administration

Goddard Space Flight Center

Greenbelt, Maryland 20771 
TM 78050

ERROR ANALYSIS FOR RELAY TYPE

SATELLITE-AIDED SEARCH AND RESCUE SYSTEMS

John W. Marini

September 1977

GODDARD SPACE FLIGHT CENTER

Greenbelt, Maryland 


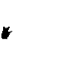




\title{
ERROR ANALYSIS FOR RELAY TYPE \\ SATELLITE-AIDED SEARCH AND RESCUE SYSTEMS
}

John W. Marini

\begin{abstract}
An analysis is made of the errors in the determination of the position of an emergency transmitter in a satellite-aided search and rescue system. The satellite is assumed to be at a height of $820 \mathrm{~km}$ in a near circular near polar orbit. Short data spans of four minutes or less are used. The error sources considered are measurement noise, transmitter frequency drift, ionospheric effects and error in the assumed height of the transmitter. The errors are calculated for several different transmitter positions, data rates and data spans. The only transmitter frequency used was $406 \mathrm{MHz}$, but the results can be scaled to different frequencies.

In a typical case, in which four Doppler measurements were taken over a span of two minutes, the position error was about $1.2 \mathrm{~km}$.
\end{abstract}


ABSTRACT ....................

INTRODUCTION. ........................ 1

MATHEMATICAL METHOD. ................. 2

SIMULATION GEOMETRY $\ldots \ldots \ldots \ldots \ldots \ldots \ldots \ldots \ldots \ldots \ldots \ldots \ldots \ldots$

RESULTS .......................... 7

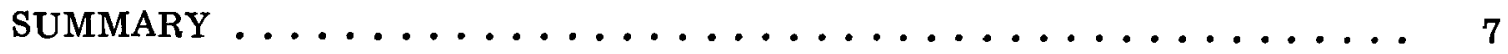

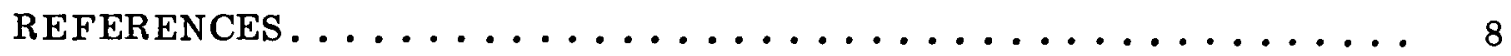

\section{TABLES}

Table

$\underline{\text { Page }}$

1 Example of Data Interval. Length $4 \mathrm{~min}$, Center TCA +2 , 7 Points, Satellite Elevation $=20^{\circ}$ at TCA . . . . . . 9

$220^{\circ}$ Satellite Elevation At Time of Closest Approach (TCA) . . 10

$350^{\circ}$ Satellite Elevation At Time of Closest Approach (TCA) . . 11

$480^{\circ}$ Satellite Elevation At Time of Closest Approach (TCA) . . 12

\section{ILLUSTRATIONS}

1 Noise Error vs. Elevation Angle, $406 \mathrm{MHz} \ldots \ldots$

2 Noise Error vs. Number of Points, $406 \mathrm{MHz}$. . . . . . 14

3 Noise Error vs. Length of Data Interval . . . . . . . 15

4 Noise Error vs. Data Center Displacement . . . . . . 16

$5 \quad$ Height Error Per Km vs. Satellite Elevation at TCA . . . . 17 


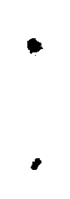




\section{ERROR ANALYSIS FOR RELAY TYPE \\ SATELLITE-AIDED SEARCH AND RESCUE SYSTEMS}

\section{INTRODUCTION}

In the operation of a satellite-aided search and rescue system, distress signals from an emergency transmitter are received by an orbiting satellite. The position of the transmitter is determined by an analysis of the Doppler shift of the frequency of the received signal.

A practical consideration is the way by which the Doppler information is transmitted back to the ground for use by a rescue team. One method is to measure and record the Doppler-shifted signal at the satellite. The record is later "dumped" when the satellite passes within view of a system ground station [1] . Another method involves no recording but instead requires the existence of a number of ground stations so positioned that the satellite has at least one of them in view when it receives the emergency transmission. In this case the Doppler information can be immediately relayed to ground station. This can be done either by measuring the Doppler shift at the satellite and encoding the measurement onto the transmission from the satellite or by merely routing the emergency signal through a transponder [1]. Both the recording and the immediate relay method may be employed in the joint U. S.-Canada tests using the TIROS-N satellite $[2,3]$.

In a search and rescue system employing the relay method, Doppler data is obtained only during the interval when the satellite is in view not only of the emergency transmitter but also of the receiving ground station. Since the number of ground stations is limited by considerations of cost, the datacollection interval may be limited to only a small portion of the satellite pass over the emergency transmitter. It therefor becomes important to determine how the accuracy of the Doppler position determination is affected by the use of short data spans. The case where data is available from the entire satellite pass has been treated by Koch [ 4 ].

A second practical consideration is the rate at which Doppler information is transmitted. Both because the satellite might be required to handle a large number of emergency signals simultaneously and also in order to reduce the average power requirements of the emergency transmitters, it is advantageous to have the transmitters operate not continuously but instead repetitively in short bursts. The selection of the repetition rate involves a trade-off, since the improvement in the signal capacity of the satellite and the reduction of the power requirement of the emergency transmitter obtained by the use of a low 
repetition rate must be weighed against the error introduced in the calculation of transmitter positions by the reduction of the number of data points.

In this report the error in the position calculation will be estimated using data spans of several durations and repetition rates for a number of transmitter locations with respect to the satellite ground track. The error sources considered will be Doppler measurement noise, assumed to be independently distributed for each point, linear drift of the emergency transmitter frequency, ionospheric effects as modeled in Reference 1, and error in the assumed height of the emergency transmitter above sea level. The latter error exists because it is usually better to estimate the transmitter height rather than solve for it when only a small quantity of Doppler data is available.

The effect of satellite ephemeris errors is not treated. It is obvious, however, that both along-track and cross-track satellite position errors that remain nearly constant over the data span will result in an approximate one-to-one displacement of the calculated transmitter position. A constant radial (height) error in satellite position would have roughly the same effect as a corresponding negative error in the emergency transmitter height assumed.

The ambiguity problem [5], the existence of an extraneous solution to the least square equations for transmitter location, is also not treated. In the mathematical method employed, position location errors are calculated under the assumption that the proper least squares solution has been determined.

\section{MATHEMATICAL METHOD}

The Doppler shift of the received signal is the difference between its frequency $f_{r}$ and that of the transmitted signal $f_{t}$. Ignoring atmospheric effects and receiver noise, the classical relationship between the Doppler shift of an uplink signal and the range rate $\dot{\rho}$ is

$$
\dot{\rho}=-\mathrm{c}\left(\mathrm{f}_{\mathrm{r}}-\mathrm{f}_{\mathrm{t}}\right) / \mathrm{f}_{\mathrm{t}}
$$

where $\mathbf{c}$ is the speed of light. In the satellite-aided search and rescue system under consideration, however, the exact frequency of the emergency transmitter ordinarily will not be known. Consequently a nominal frequency $f_{n}$ must be used in (1) to calculate the range rate. Defining the range-rate so calculated to be the observed range rate $\dot{\rho}_{\mathrm{o}}$

$$
\dot{\rho}_{0}=-c \frac{f_{r}-f_{n}}{f_{n}}
$$


Taking the difference between (1) and (2)

$$
\dot{\rho}-\dot{\rho}_{\mathrm{o}}=-\mathrm{c} \frac{\mathrm{f}_{\mathrm{r}}\left(\mathrm{f}_{\mathrm{n}}-\mathrm{f}_{\mathrm{t}}\right)}{\mathrm{f}_{\mathrm{t}} \mathrm{f}_{\mathrm{n}}}
$$

Since the fractional variation in the received signal is small, the right hand side of (3) may be approximated* by a constant provided that the nominal frequency used is close to the transmitted frequency and that the latter is sufficiently stable over the duration of the satellite pass. Consequently the range rate observed at the time of the $i$ 'th Doppler measurement is modeled as the sum

$$
\dot{\rho}_{\mathrm{oi}} \doteq \dot{\rho}_{\mathrm{i}}+\mathrm{b}
$$

where $\dot{\rho}_{\mathrm{i}}$ is the true range rate and $\mathrm{b}$ is an unknown fixed bias arising from the use of a nominal transmitter frequency in the calculation of $\dot{\rho}_{\mathrm{oi}}$. The relationships (4) hold only approximately because of measurement noise, neglect of atmospheric effects on propagation, and other modeling errors.

The procedure usually employed to solve the family of equations (4) for the unknown transmitter position is the method of least squares. Since the satellite ephemeris is assumed known, the range rate $\dot{\rho}_{\mathrm{i}}$ between the satellite and a given transmitter position becomes a function of transmitter position alone

$$
\dot{\rho}_{\mathrm{i}}=\dot{\rho}_{\mathrm{i}}(\phi, \lambda, \mathrm{h})
$$

where $\phi$ and $\lambda$ are the transmitter latitude and longitude respectively, and $h$ is the height above the surface of an ellipsoidal Earth. In a single pass solution, the height of the transmitter is usually not solved for but instead is taken to be some assumed value $h_{\mathrm{a}}$. The least squares solution of (4) consists, then, of the values $\hat{\phi}, \hat{\lambda}$, and $\hat{b}$ that minimize the sum of squares

$$
\mathrm{S}=\sum_{\mathrm{i}}^{\sum}\left[\dot{\rho}_{\mathrm{oi}}-\dot{\rho}_{\mathrm{i}}\left(\hat{\phi}, \hat{\lambda}, \mathrm{h}_{\mathrm{a}}\right)-\hat{\mathrm{b}}\right]^{2}
$$

\footnotetext{
*This approximation, which is often used $[1,4]$ simplifies the least squares equations for determining the position of the transmitter. It is not a requirement, however, since the more accurate equation $\left(1-\dot{\rho}_{r}\right) f_{t}=f_{r}$, where $f_{t}$ is treated as an unknown constant, can also be solved by non-linear least squares.
} 
The method used here to determine the magnitudes of the errors

$$
\begin{aligned}
\Delta \phi & =\hat{\phi}-\phi \\
\Delta \lambda & =\hat{\lambda}-\lambda \\
\Delta \mathrm{b} & =\hat{\mathrm{b}}-\mathrm{b}
\end{aligned}
$$

does not employ actual observed data, of course. Instead the position coordinates $\phi, \lambda, \mathrm{h}$ are chosen, and the observed range rate is taken to be the sum of the true range rate $\dot{\rho}(\phi, \lambda, \mathrm{h})$, an error term $\epsilon_{\mathrm{i}}$, and optionally a bias term $\mathrm{b}$.

$$
\dot{\rho}_{\mathrm{oi}} \equiv \dot{\rho}_{\mathrm{i}}(\phi, \lambda, \mathrm{h})+\mathrm{b}+\epsilon_{\mathrm{i}}
$$

Substituting (8) into (6), and linearly expanding $\dot{\rho}_{\mathrm{i}}\left(\hat{\phi}, \hat{\lambda}, \mathrm{h}_{\mathrm{a}}\right)$ about the values $\phi, \lambda, h$ the sum of squares $(6)$ becomes approximately

$$
\mathrm{S} \doteq{ }_{\mathrm{i}}\left[\epsilon_{\mathrm{i}}+\frac{\partial \dot{\rho}_{\mathrm{i}}}{\partial \mathrm{h}}\left(\mathrm{h}-\mathrm{h}_{\mathrm{a}}\right)-\frac{\partial \dot{\rho}_{\mathrm{i}}}{\partial \phi} \Delta \phi-\frac{\partial \dot{\rho}_{\mathrm{i}}}{\partial \lambda} \Delta \lambda-\Delta \mathrm{b}\right]^{2}
$$

The minimization of (9) is a standard problem in linear least squares. Using the matrix notation

$$
\mathrm{A} \equiv\left[\begin{array}{ccc}
\frac{\partial \dot{\rho}_{1}}{\partial \phi} & \frac{\partial \dot{\rho}_{1}}{\partial \lambda} & 1 \\
\frac{\partial \dot{\rho}_{2}}{\partial \phi} & \frac{\partial \dot{\rho}_{2}}{\partial \lambda} & 1 \\
\dot{\cdot} & \cdot & \cdot \\
\frac{\partial \dot{\rho}_{\mathrm{n}}}{\partial \phi} & \frac{\partial \dot{\rho}_{\mathrm{n}}}{\partial \lambda} & 1
\end{array}\right]
$$




$$
\mathrm{Y} \equiv\left[\begin{array}{c}
\epsilon_{1} \\
\epsilon_{2} \\
\cdot \\
\cdot \\
\epsilon_{\mathrm{n}}
\end{array}\right]+\left(\mathrm{h}-\mathrm{h}_{\mathrm{a}}\right)\left[\begin{array}{c}
\partial \dot{\rho}_{1} / \partial \mathrm{h} \\
\partial \dot{\rho}_{2} / \partial \mathrm{h} \\
\dot{\cdot} \\
\partial \dot{\rho}_{\mathrm{n}} / \partial \mathrm{h}
\end{array}\right]
$$

where $\mathrm{n}$ is the number of Doppler measurements, the minimizing values of $\Delta \phi$, $\Delta \lambda$, and $\Delta b$ are given by

$$
X=\left(A^{T} A\right)^{-1} A^{T} Y
$$

$\mathrm{A}^{\mathrm{T}}$ being the transpose of the matrix $\mathrm{A}$.

Equation (13) is used to calculate the errors caused by oscillator drift, neglect of ionospheric effects, and error in assumed height. To determine the effect of a constant transmitted frequency $\mathrm{drift}_{\mathrm{df}} \mathrm{t} / \mathrm{dt}$, for example, the components of $\mathrm{Y}$ are set equal to

$$
Y_{i}=-c \frac{\left(d f_{t} / d t\right)}{f_{n}} t_{i}
$$

and equation (14) is solved for X for each selected tramsmitter position $(\phi, \lambda, h)$. Similarly ionospheric effects are calculated by setting

$$
\mathrm{Y}_{\mathrm{i}}=\Delta \dot{\mathrm{R}}_{\mathrm{i}}
$$

where $\Delta \dot{R}_{i}$ is the ionospheric correction given in Reference 1. An electron content of $6.5 \times 10^{17}$ electrons per square meter was used.

The effect of a 1 kilometer error in the assumed height $h_{a}$ is calculated from the value of $\mathrm{Y}$ obtained by setting $\mathrm{h}-\mathrm{h}_{\mathrm{a}}=1 \mathrm{~km}$ and $\epsilon_{\mathrm{i}}=0$ in (12). 
To determine the effect of measurement noise on $\Delta \phi$ and $\Delta \lambda$, one takes the outer matrix product of $\mathrm{X}$ with itself. From equation (13)

$$
X X^{T}=\left(A^{T} A\right)^{-1} A^{T} Y Y^{T} A\left(A^{T} A\right)^{-1}
$$

The range-rate error is related to frequency error by the equation

$$
\epsilon_{\mathrm{i}}=-\left(\mathrm{c} / \mathrm{f}_{\mathrm{n}}\right) \epsilon_{\mathrm{fi}}
$$

where $\epsilon_{\mathrm{fi}}$ is the error in the i'th measurement of the Doppler frequency. The errors $\epsilon_{\mathrm{fi}}$ are assumed to be independent with mean zero and a standard deviation $\sigma_{\mathrm{f}}$. It follows that the range-rate noise errors $\epsilon_{\mathrm{i}}$ are independently distributed with zero mean and the standard deviation $\sigma$

$$
\sigma=\left(\mathrm{c} / \mathrm{f}_{\mathrm{n}}\right) \sigma_{\mathrm{f}}
$$

Hence the expected value of the product $\mathrm{YY}^{\mathrm{T}}$ that appears in (16) is simply the identity matrix times the variance $\sigma^{2}$. Taking the expected value of both sides of (16), therefore, gives

$$
\mathrm{E}\left[\mathrm{XX} \mathrm{T}^{\mathrm{T}}\right]=(\mathrm{A} \tilde{\mathrm{A}})^{-1} \sigma^{2}
$$

Consequently the covariance matrix of the position and bias errors per unit variance in range rate is $(\tilde{\mathrm{A}} \mathrm{A})^{-1}$, and the standard deviations of $\Delta \phi$ and $\Delta \lambda$ per unit standard deviation in range-rate noise are given respectively by the square roots of the first and second diagonal elements of the matrix $(\tilde{\mathrm{A}} \mathrm{A})^{-1}$.

\section{SIMULATION GEOMETRY}

A circular orbit, similar to that planned for TIROS-N, with a radius of 7200 kilometers and an inclination of $98.7^{\circ}$ was used in the simulations. The exact latitudes of the transmitter positions had little effect on the results. All of the positions used had latitudes of about $34^{\circ} \mathrm{N}$. 
Three transmitter positions were used to obtain the results given in Tables 1-4. These positions were taken so that the satellite elevations as seen by an observer located at the transmitters were $20^{\circ}, 50^{\circ}$, and $80^{\circ}$ at the time of closest approach (TCA) of the satellite to the transmitter.

\section{RESULTS}

The Doppler data used in the error analysis consisted of points taken at equal intervals over intervals of 1,2 , or 4 minutes. In Table 1 , an example is given at a 2 minute data interval consisting of seven Doppler points. The interval is centered at two minutes after TCA. Tables 2-4 show the results of the error analysis for each of the three stations. In Figures 1-4 the error caused by measurement noise is plotted as a function of elevation angle, number of points, length of the data interval, and data center displacement respectively. In the case of a large number of points, the noise error should be inversely proportional to the square root of that number, as shown in Figure 2.

In Figure 5, height error is shown as a function of elevation angle. The curve is roughly approximated by the tangent of the elevation angle.

The transmitter frequency was $406 \mathrm{MHz}$ in all cases, but the results are easily scaled to other frequencies. Height error is independent of frequency. Noise and drift errors are scaled to a new frequency $f$ by multiplying by the factor $(406 / f)$, as follows from equations (17) and (14). Ionospheric effects vary as the inverse square of the frequency, the scaling factor being $(406 / f)^{2}$. They also vary directly with the integrated electron density used. Ionospheric error can be reduced, of course, by incorporating an ionospheric model in the least squares solution.

The largest number of points used in a data interval was seven. Drift, height, and ionospheric errors show little variation with the number of data points per interval. Noise error for a larger number of points $n$ may be estimated by multiplying the result for seven points by the factor $\sqrt{ } 7 / \mathrm{n}$.

As a numerical example, consider a $406 \mathrm{MHz}$ transmitter whose drift rate is about 10 Hertz over 10 minutes. Assume that the transmitter is known to be at sea level, and that the standard deviation of the received signal is $0.29 \mathrm{~Hz}$, corresponding to a determination that the frequency falls with uniform probability within a one Hertz band. If the maximum elevation angle is $20^{\circ}$; and if four points are measured over a two minute interval centered at the time of closest approach, then the noise, drift, and height errors are $0.78,0.87$, and 0 respectively. The ionospheric error varies directly with the electron content, and would probably be less than $0.32 \mathrm{~km}$, which can be ignored. The expected value of the error is estimated by taking the square root of the sum of the squares of the individual errors, giving about $1.2 \mathrm{~km}$. 


\section{SUMMARY}

An analysis has been made of the errors in the determination of the position of an emergency transmitter in a satellite-aided search and rescue system. The analysis assumed a satellite at a height of $820 \mathrm{~km}$ in a near circular near polar orbit. Short data intervals of four minutes or less were used. Calculations were carried out assuming a $406 \mathrm{MHz}$ signal, but the results can easily be scaled to other frequencies. Enough cases were treated to make possible at least a rough interpolation of the results to different data rates and different transmitter locations.

\section{REFERENCES}

1. P. E. Schmid, J. J. Lynn, and F. O. Vonbun, "Single Pass Doppler Positioning for Search and Rescue Satellite Missions," IEEE 1976 Position Location and Navigation Symposium, ... Nov. , 1976.

2. Aviation Week and Space Technology, Jan. 24, 1977; p. 24.

3. Aviation Week and Space Technology, March 28, 1977; pp. 23-24.

4. D. W. Koch, "Error Analysis for Satellite-Aided Search and Rescue," GSFC X-932-76-86, Aug. 1976.

5. T. Green, "Satellite Doppler Data Processing for Platform Navigation," IEEE Trans. on Geoscience Electronics, Vol. GE-13, No. 1, Jan. 1975; pp. 28-38. 
Table 1

Example of Data Interval. Length: $4 \mathrm{~min}$, Center: TCA + 2, 7 Points, Satellite Elevation: $20^{\circ}$ at TCA.

\begin{tabular}{|c|c|c|}
\hline Time & Elevation & Range Rate \\
\hline $9^{\prime} 40^{\prime \prime}$ & $20^{\circ}$ & $0 \mathrm{Km} / \mathrm{sec}$ \\
$10^{\prime} 20^{\prime \prime}$ & $19.6^{\circ}$ & $1.05 \mathrm{Km} / \mathrm{sec}$ \\
$11^{\prime}$ & $18.3^{\circ}$ & $2.02 \mathrm{Km} / \mathrm{sec}$ \\
$11^{\prime} 40^{\prime \prime}$ & 16.5 & $2.88 \mathrm{Km} / \mathrm{sec}$ \\
$12^{\prime} 20^{\prime \prime}$ & $14.3^{\circ}$ & $3.59 \mathrm{Km} / \mathrm{sec}$ \\
$13^{\prime}$ & $11.9^{\circ}$ & $4.17 \mathrm{Km} / \mathrm{sec}$ \\
$13^{\prime} 40^{\prime \prime}$ & $9.5^{\circ}$ & $4.63 \mathrm{Km} / \mathrm{sec}$ \\
\hline
\end{tabular}


Table 2

$20^{\circ}$ Satellite Elevation At Time of Closest Approach (TCA)

Station Latitude $=36.0^{\circ}$

Frequency $=406 \mathrm{MHz}$

\begin{tabular}{|c|c|c|c|c|c|c|c|c|}
\hline$\overline{\mathrm{DA}}$ & A INTERI & & SATEL & $\mathrm{EL}$ (deg) & & RSS POSITION & ATION EI & $(\mathrm{Km})$ \\
\hline LENGTH & CENTER & \# PTS. & 1st PT. & LAST PT. & $\begin{array}{l}\text { NOISE } \\
\text { Per } \mathrm{Hz}\end{array}$ & $\begin{array}{c}\text { DRIFT } \\
\text { Per } 0.1 \mathrm{~Hz} / \mathrm{min}\end{array}$ & $\begin{array}{l}\text { HEIGHT } \\
\text { Per Km }\end{array}$ & $\begin{array}{c}\text { IONOSPHERIC } \\
6.5 \times 10^{17} \text { elect. } / \mathrm{m}^{2}\end{array}$ \\
\hline $1 \mathrm{~min}$ & TCA & 3 & 19.8 & 19.8 & 10.9 & 0.083 & 0.61 & 0.32 \\
\hline & & 7 & & & 8.8 & 0.082 & 0.61 & 0.32 \\
\hline & $\mathrm{TCA}+2$ & 3 & 17.9 & 14.8 & 20.1 & 0.085 & 0.56 & 0.32 \\
\hline & & 4 & & & 18.4 & 0.085 & 0.56 & 0.32 \\
\hline & & 4 & & & 54.3 & 0.21 & 0.52 & 1.18 \\
\hline & & 7 & & & 47.3 & 0.20 & 0.52 & 1.18 \\
\hline $2 \min$ & TCA & 3 & 19.0 & 19.0 & 2.9 & 0.088 & 0.61 & 0.33 \\
\hline & & 4 & & & 2.7 & 0.087 & 0.61 & 0.32 \\
\hline & & 7 & & & 2.3 & 0.086 & 0.61 & 0.32 \\
\hline & $\mathrm{TCA}+2$ & 3 & 19.0 & 13.1 & 5.2 & 0.088 & 0.57 & 0.33 \\
\hline $4 \mathrm{~min}$ & TCA & 3 & 16.5 & 16.5 & 0.93 & 0.108 & 0.63 & 0.35 \\
\hline & & 4 & & & 0.87 & 0.104 & 0.63 & 0.35 \\
\hline & & 7 & & & 0.75 & 0.100 & 0.62 & 0.34 \\
\hline & $\mathrm{TCA}+2$ & 3 & 20 & 9.5 & 1.44 & 0.101 & 0.58 & 0.34 \\
\hline & & 4 & & & 1.31 & 0.098 & 0.58 & 0.34 \\
\hline & & 7 & & & 1.13 & 0.095 & 0.58 & 0.34 \\
\hline & $\mathrm{TCA}+4$ & 3 & 16.5 & 2.6 & 3.8 & 0.20 & 0.53 & 1.06 \\
\hline & & 4 & & & 3.3 & 0.188 & 0.53 & 0.97 \\
\hline & & 7 & & & 2.8 & 0.182 & 0.53 & 0.96 \\
\hline
\end{tabular}


Table 3

$50^{\circ}$ Satellite Elevation At Time of Closest Approach (TCA)

Station Latitude $=35.0^{\circ}$

Frequency $=406 \mathrm{MHz}$

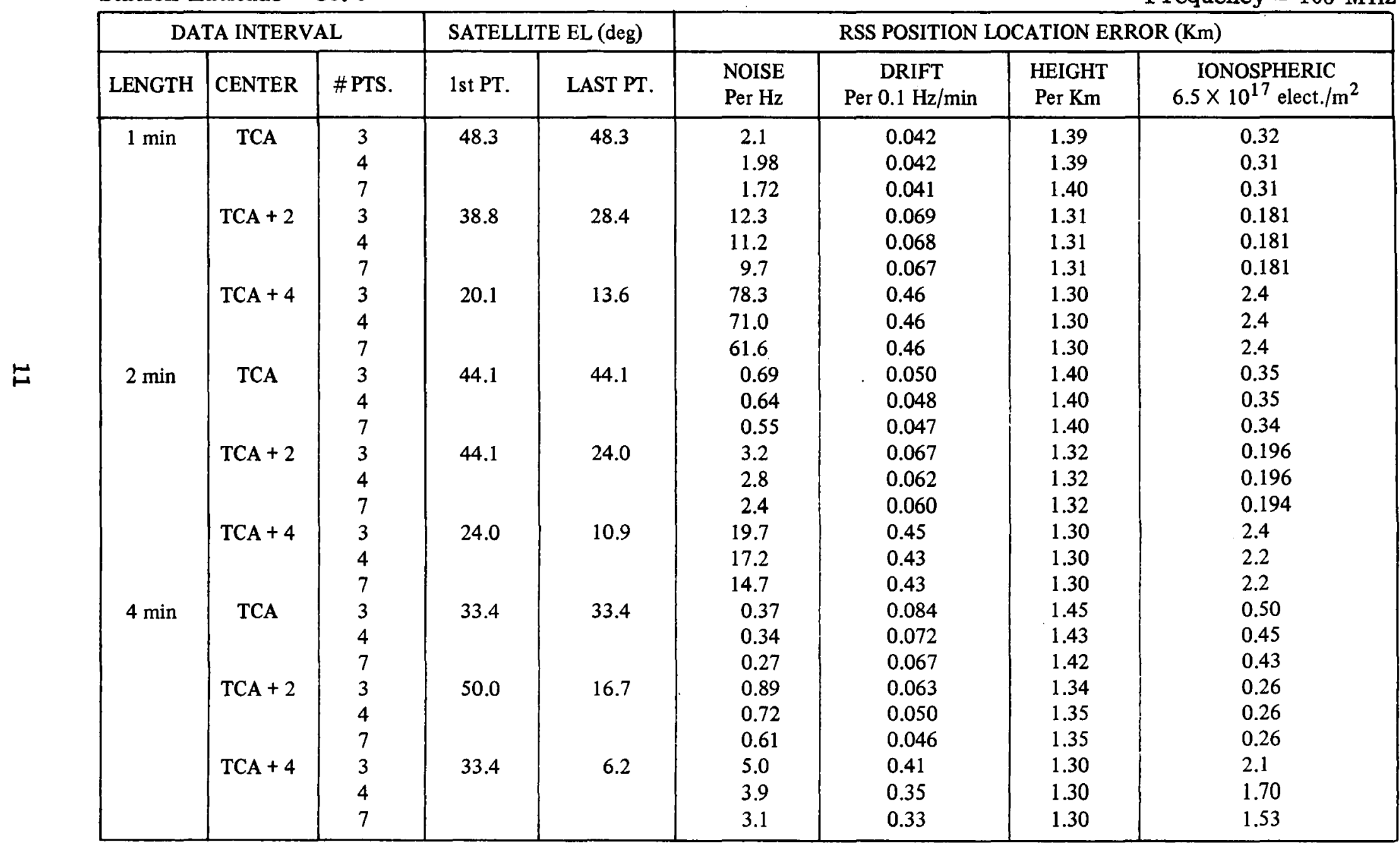


Table 4

$80^{\circ}$ Satellite Elevation At Time of Closest Approach (TCA)

Station Latitude $=34.2^{\circ}$

Frequency $=406 \mathrm{MHz}$

\begin{tabular}{|c|c|c|c|c|c|c|c|c|}
\hline \multicolumn{3}{|c|}{ DATA INTERVAL } & \multicolumn{2}{|c|}{ SATELLITE EL (deg) } & \multicolumn{4}{|c|}{ RSS POSITION LOCATION ERROR (Km) } \\
\hline LENGTH & CENTER & \# PTS. & 1st PT. & LAST PT. & $\begin{array}{l}\text { NOISE } \\
\text { Per } \mathrm{Hz}\end{array}$ & $\begin{array}{c}\text { DRIFT } \\
\text { Per } 0.1 \mathrm{~Hz} / \mathrm{min}\end{array}$ & $\begin{array}{l}\text { HEIGHT } \\
\text { Per Km }\end{array}$ & $\begin{array}{c}\text { IONOSPHERIC } \\
6.5 \times 10^{17} \text { elect. } / \mathrm{m}^{2}\end{array}$ \\
\hline \multirow{6}{*}{$1 \mathrm{~min}$} & & 4 & & & 1.68 & 0.099 & 6.0 & 0.93 \\
\hline & & 7 & & & 1.42 & 0.098 & 6.0 & 0.92 \\
\hline & $\mathrm{TCA}+2$ & 3 & 48.7 & 32.8 & 37 & 0.28 & 5.9 & 0.23 \\
\hline & & 4 & & & 33 & 0.27 & 5.9 & 0.23 \\
\hline & & 4 & & & 259 & 2.1 & 6.2 & 9.5 \\
\hline & & 7 & & & 224 & 2.1 & 6.2 & 9.4 \\
\hline \multirow[t]{5}{*}{$2 \mathrm{~min}$} & TCA & 3 & 59.5 & 59.5 & 0.97 & 0.128 & 6.0 & 1.10 \\
\hline & & 4 & & & 0.89 & 0.122 & 6.0 & 1.07 \\
\hline & & 7 & & & 0.72 & 0.117 & 6.0 & 1.04 \\
\hline & $\mathrm{TCA}+2$ & 3 & 59.5 & 27.1 & 9.6 & 0.26 & 5.9 & 0.30 \\
\hline & & 7 & & & 53 & 1.90 & 6.1 & 8.5 \\
\hline \multirow[t]{9}{*}{$4 \mathrm{~min}$} & TCA & 3 & 39.9 & 39.9 & 0.92 & 0.26 & 6.1 & 1.74 \\
\hline & & 4 & & & 0.73 & 0.20 & 6.1 & 1.44 \\
\hline & & 7 & & & 0.56 & 0.182 & 6.1 & 1.37 \\
\hline & $\mathrm{TCA}+2$ & 3 & 80 & 18.3 & 2.7 & 0.190 & 5.9 & 0.60 \\
\hline & & 4 & & & 1.93 & 0.104 & 5.9 & 0.58 \\
\hline & & 7 & & & 1.59 & 0.086 & 5.9 & 0.59 \\
\hline & $\mathrm{TCA}+4$ & 3 & 39.9 & 6.8 & 19.3 & 1.86 & 6.1 & 8.9 \\
\hline & & 4 & & & 14.1 & 1.55 & 6.1 & 6.6 \\
\hline & & 7 & & & 10.8 & 1.40 & 6.1 & 5.7 \\
\hline
\end{tabular}




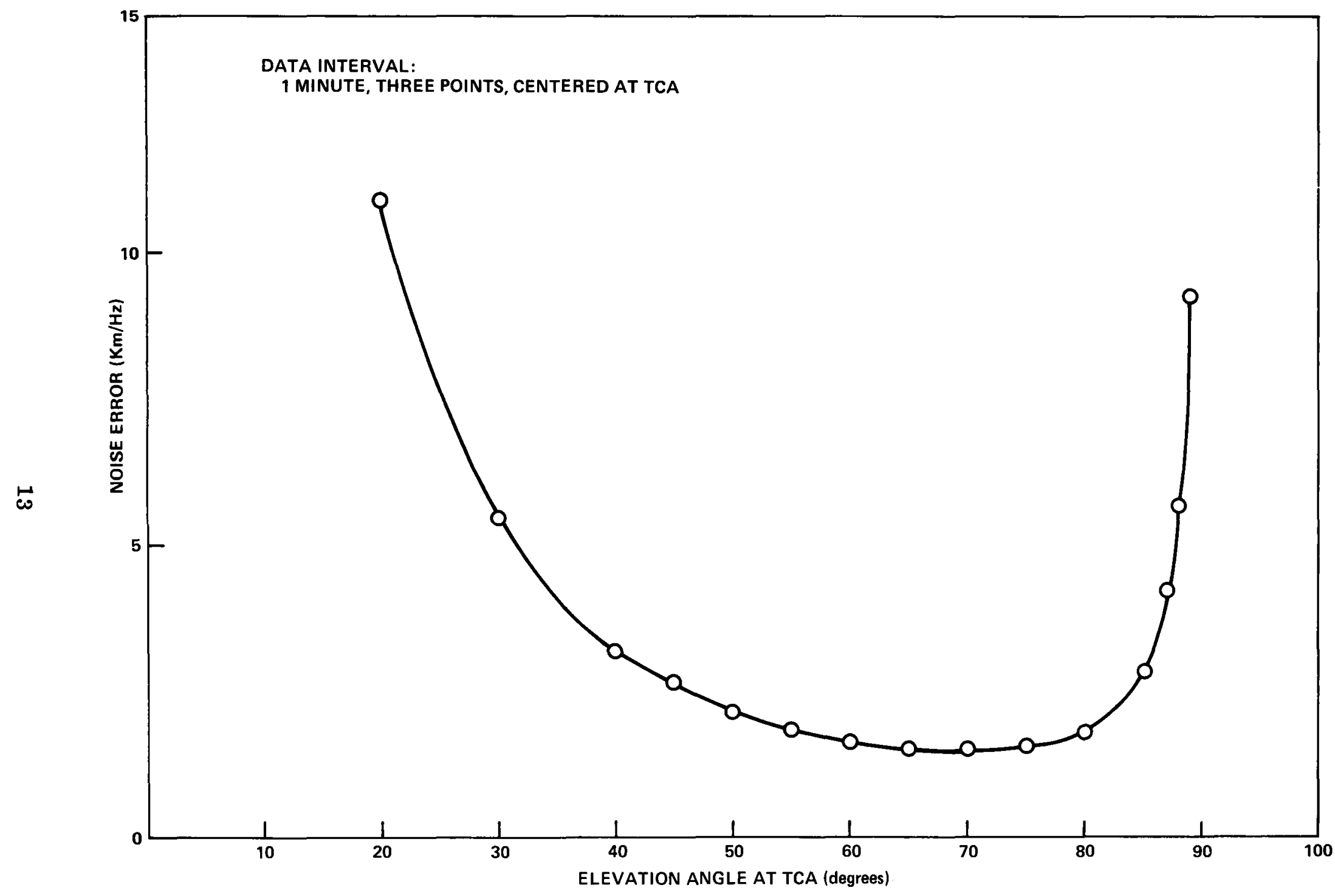

Figure 1. Noise Error vs. Elevation Angle, $406 \mathrm{MHz}$ 


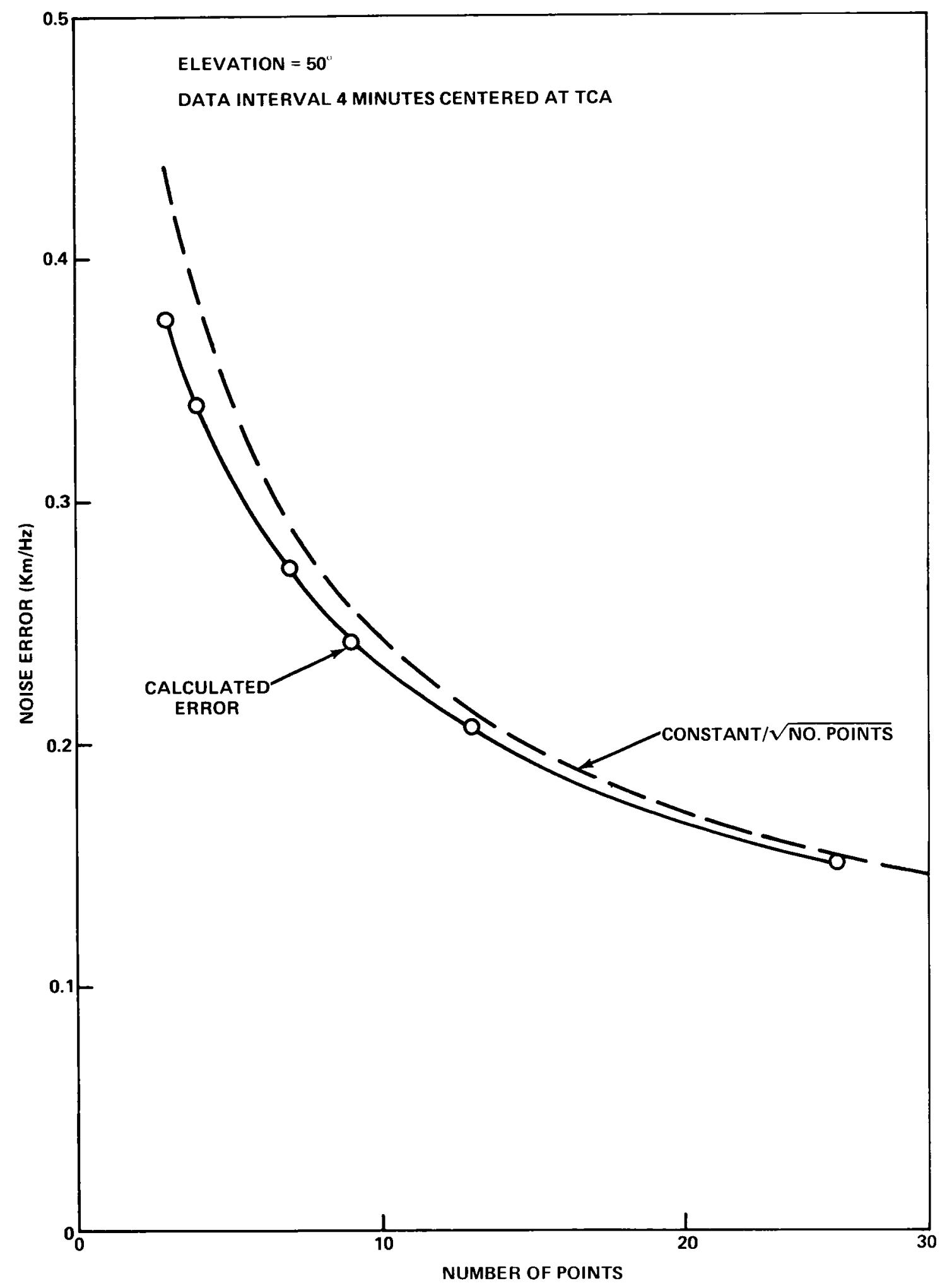

Figure 2. Noise Error vs. Number of Points, $406 \mathrm{MHz}$ 


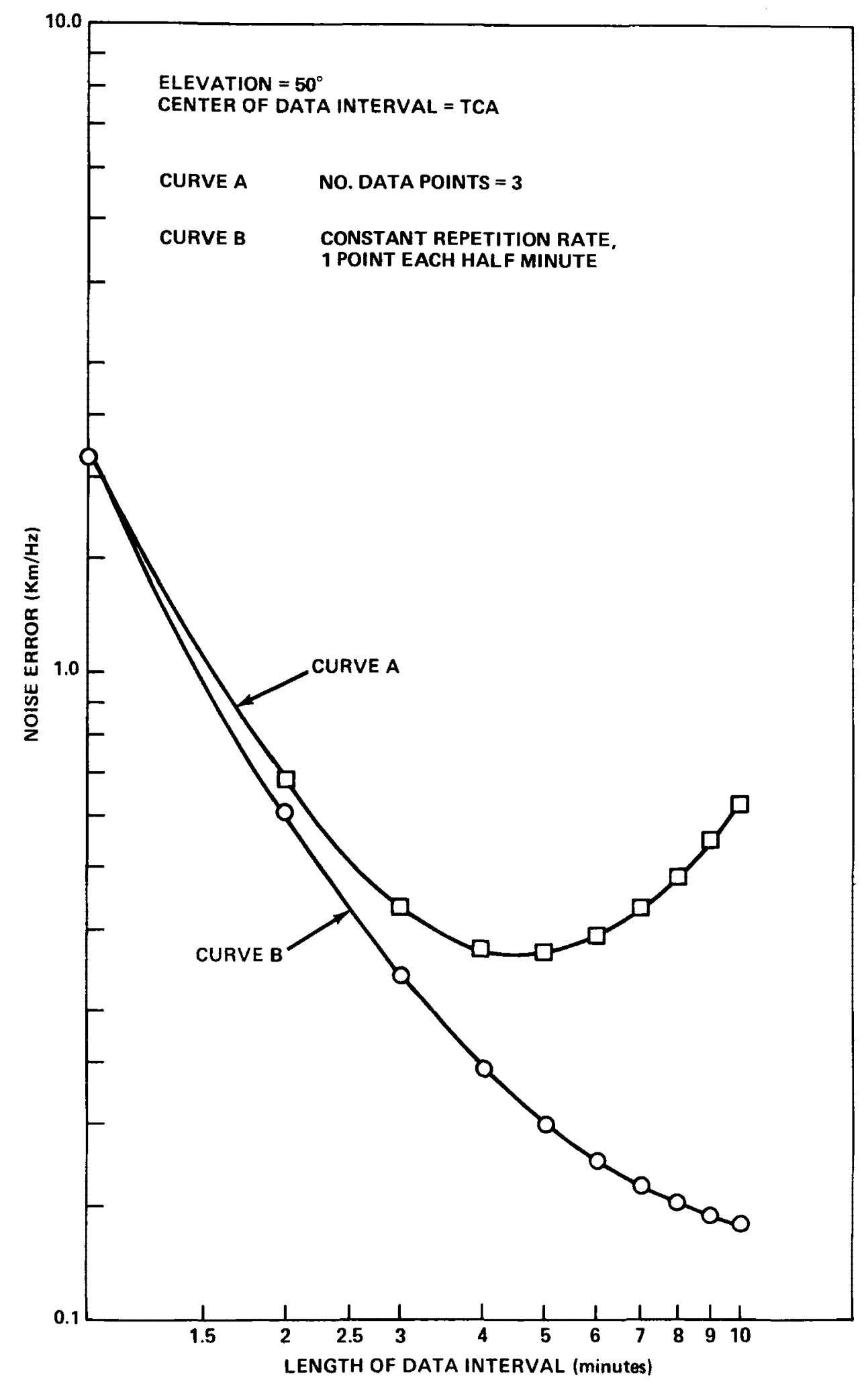

Figure 3. Noise Error vs. Length of Data Interval 


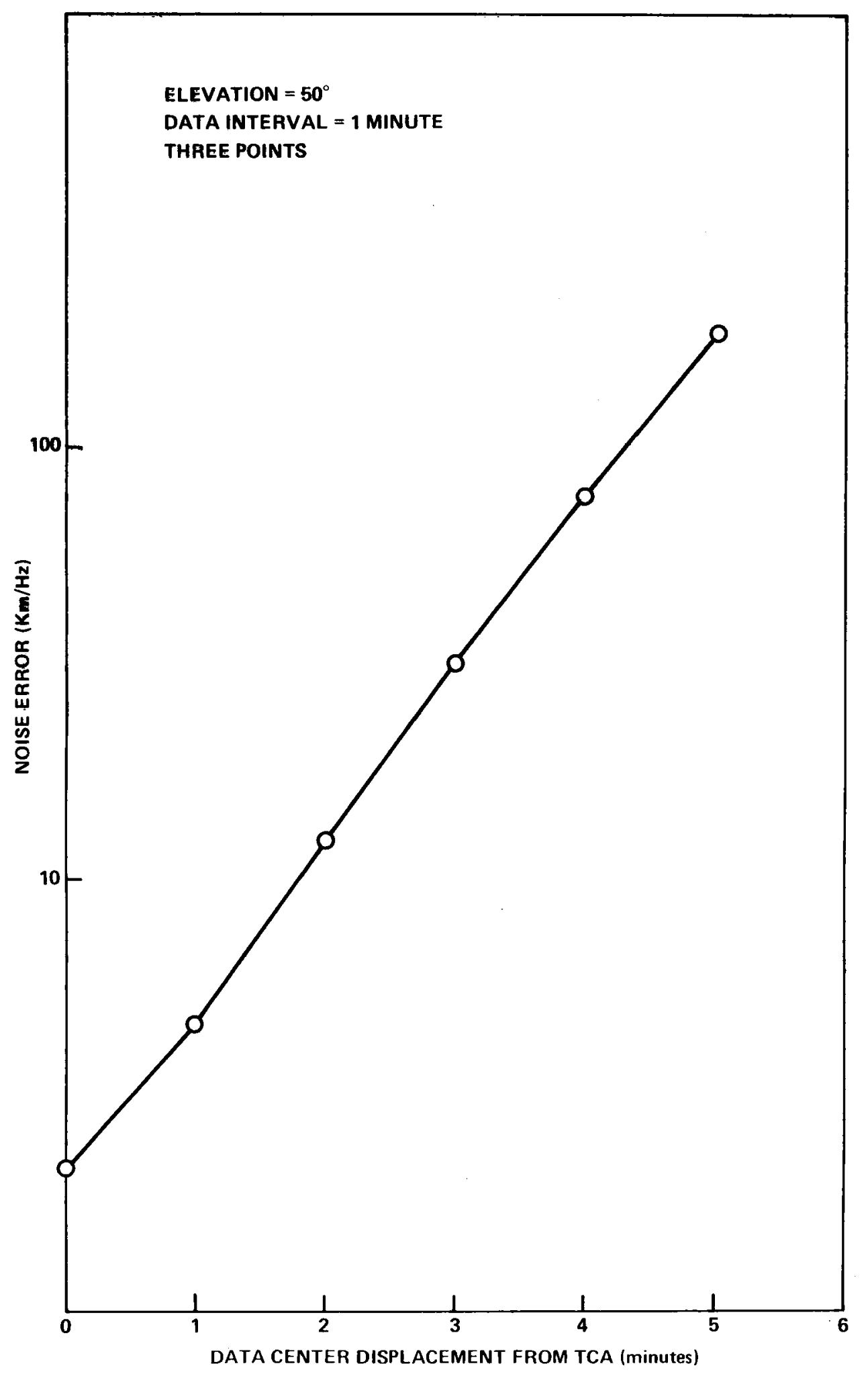

$\bullet$ 


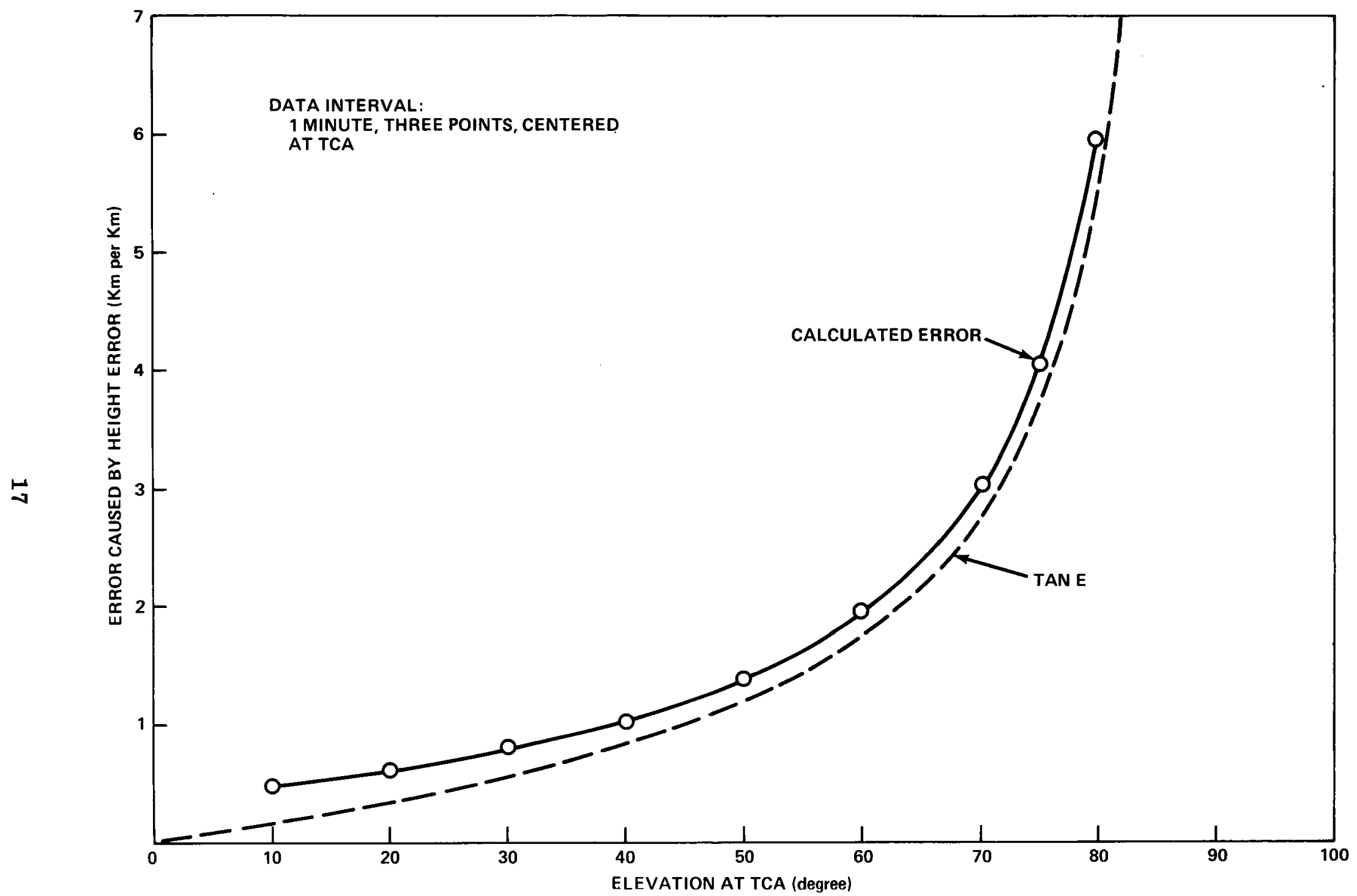

Figure 5. Height Error Per Km vs. Satellite Elevation at TCA 


$$
\text { . }
$$$$
\text { . }
$$ 


\section{BIBLIOGRAPHIC DATA SHEET}

\begin{tabular}{|c|c|c|}
\hline $\begin{array}{l}\text { 1. Report No. } \\
\text { TM } 78050\end{array}$ & 2. Government Accession No. & 3. Recipient's Catalog No. \\
\hline \multirow{2}{*}{\multicolumn{2}{|c|}{$\begin{array}{l}\text { 4. Title and Subtitle } \\
\text { Error Analysis for Relay Type Satellite Aided } \\
\text { Search and Rescue Systems }\end{array}$}} & $\begin{array}{l}\text { 5. Report Date } \\
\text { September } 1977\end{array}$ \\
\hline & & 6. Performing Organization Code \\
\hline \multicolumn{2}{|c|}{$\begin{array}{l}\text { 7. Author(s) } \\
\text { John W. Marini }\end{array}$} & 8. Performing Organization Report No. \\
\hline \multicolumn{2}{|c|}{ 9. Performing Organization Name and Address } & 10. Work Unit No. \\
\hline \multirow{2}{*}{\multicolumn{2}{|c|}{$\begin{array}{l}\text { Goddard Space Flight Center } \\
\text { Greenbelt, Maryland }\end{array}$}} & 11. Contract or Grant No. \\
\hline & & 13. Type of Report and Period Covered \\
\hline \multirow{2}{*}{\multicolumn{2}{|c|}{ 12. Sponsoring Agency Name and Address }} & $\begin{array}{l}\text { Technical Memorandum } \\
\text { September } 1977\end{array}$ \\
\hline & & 14. Sponsoring Agency Code \\
\hline
\end{tabular}

15. Supplementary Notes

16. Abstract

An analysis is made of the errors in the determination of the position of an emergency transmitter in a satellite-aided search and rescue system. The satellite is assumed to be at a height of $820 \mathrm{~km}$ in a near circular near polar orbit. Short data spans of four minutes or less are used. The error sources considered are measurement noise, transmitter frequency drift, ionospheric effects and error in the assumed height of the transmitter. The errors are calculated for several different transmitter positions, data rates and data spans. The only transmitter frequency used was $406 \mathrm{MHz}$, but the results can be scaled to different frequencies.

In a typical case, in which four Doppler measurements were taken over a span of two minutes, the position error was about $1.2 \mathrm{~km}$.

17. Key Words (Selected by Author(s))

18. Distribution Statement

Error Analysis

Search and Rescue

19. Security Classif. (of this report)

20. Security Classif. (of this page)

21. No. of Pages

22. Price*

Unclassified

Unclassified

20

-For sale by the National Technical Information Service, Springfield, Virginia 22151. 


$$
\text { : }
$$


